\title{
A supervitalidade como forma de poder: um olhar a partir das academias de ginástica
}

\author{
Fábio Luís Santos Teixeira* \\ Iraquitan de Oliveira Caminha**
}

\begin{abstract}
Resumo: Neste estudo compreendemos a supervitalidade como conseqüência da biopolítica. Atualmente, não buscamos apenas proteger a vida, mas sim maximizá-la tornando-a mais poderosa. $\mathrm{O}$ objetivo da investigação é analisar as formas de manifestação da supervitalidade em academias de ginástica. Utilizando as teorias de Foucault e Virilio, percebemos que os sujeitos investem biotecnologicamente sobre o corpo para ter poder, aperfeiçoando suas funções biológicas e sociais.
\end{abstract}

Palavras-chave: Supervitalidade. Poder. Biopolítica. Academias de ginástica.

\section{INTRODUÇÃO}

Desde que a vida se tornou objeto de dominação política, inaugurou-se nas sociedades ocidentais modernas uma demanda pela construção de tecnologias de dominação voltadas à produção de corpos disciplinados, produtivos e dóceis (FOUCAULT, 2004).

Atualmente, quando as sociedades ocidentais vivem sobre a égide do capitalismo industrial e informacional ${ }^{1}$, percebe-se uma modificação no sentido da produção de corpos referente à instalação de uma nova tendência biopolítica que valoriza a maximização

\footnotetext{
*Graduado em Educação Física pela UPE. Mestrando em Educação Física UPE/UFPB. Recife, PE, Brasil. E-mail: fabioesef@hotmail.com

**Graduado em Educação Física pela UFPB. Mestre em filosofia pela UFPB e doutor em filosofia pela Université Catholique de Louvain. Professor-pesquisador do Mestrado em Educação Física UPE/UFPB. João Pessoa, PB, Brasil. E-mail: iraqui@uol.com.br

1Justificamos a referência ao capitalismo industrial e informacional devido à atual introdução das máquinas digitais e recente valorização da informação e do trabalho mental em detrimento do esforço físico (NORA; MINC, 1980). Entendemos que as consequências desta nova dinâmica social encontram-se associadas à busca pela supervitalidade devido à necessidade de melhorar o rendimento perceptivo para assimilar mais informações, e devido ao crescimento do sedentarismo promovido pela diminuição da mobilidade dos sujeitos na contemporaneidade.
} 
da vida humana a partir da estimulação dos sentidos e da intervenção biotecnológica sobre o corpo. Atendendo às demandas de desenvolvimento econômico desta era industrial, assistimos à ascensão de uma revolução dos transplantes e próteses biotecnológicas que possibilitam um "povoamento" tecnológico do corpo em suas dimensões micro e macrofísicas. Este povoamento revela a necessidade fundamental que os sujeitos contemporâneos têm de obter poder por meio da fruição das sensações corporais ou da melhoria das suas funções biológicas e sociais.

Nas palavras de Virilio (1996), o que está em jogo é produzir uma supervitalidade a qual corresponde à melhoria calculada do desempenho do corpo, agora entendido como um motor.

[...] não queremos mais somente viver melhor, com o conforto e consumo de bens ou de medicamentos, mas viver mais fortemente, desenvolver a intensidade nervosa da vida através da ingestão de produtos biotecnológicos que complementariam assim os alimentos e outros produtos químicos mais ou menos estimulantes (VIRILIO 1996, p. 107).

O reconhecimento de que a supervitalidade rege as sociedades ocidentais contemporâneas parece confirmar a idéia de que a busca pelo poder não reside somente na esfera política e econômica da cultura, mas sim na estimulação, na velocidade e na excitação do próprio corpo. Nessa perspectiva, concordamos com Foucault (1999; 2006) para quem o presente quadro de "culto à boa forma" resulta de um processo histórico o qual transformou os investimentos sobre o corpo em estratégia de poder. Segundo o autor, a estimulação atua sobre o corpo tornando-o cada vez mais poderoso e capaz de exercer autocontrole.

Mesmo reconhecendo a hipótese de que quanto mais o corpo é investido mais ele adquire poder, ressaltamos a necessidade de questionar sobre os rumos da supervitalidade, sobretudo, no que diz respeito às suas conseqüências socioculturais. Assim, levantamos as seguintes questões: como a supervitalidade interfere no corpo dos 
sujeitos? A partir de que práticas corporais seria possível adquirir supervitalidade? Que poderes os sujeitos pretendem atingir modificando seu corpo biotecnologicamente ou buscando práticas de superexcitação?

Para responder estas questões, utilizamos as teorias de Virilio (1996) e Foucault $(2004 ; 2006)$ no sentido de analisar as manifestações da supervitalidade e identificar as relações de poder que fundamentam o seu funcionamento à luz dos discursos de mulheres praticantes de exercício físico em academias de ginástica da cidade do Recife.

Procuramos discutir como a supervitalidade se manifesta nas academias de ginástica a partir da sua estrutura de funcionamento e das práticas corporais por elas oferecidas. Consideramos que a investigação, a partir das academias de ginástica, pode oferecer subsídios para compreender as manifestações da supervitalidade na sociedade como um todo.

Nos próximos momentos, apresentamos detalhes sobre a metodologia utilizada, abordando os aspectos relativos aos sujeitos da pesquisa, ao instrumento e à técnica de análise de discurso. Depois disso, discutimos a supervitalidade como forma de poder, focalizando os aspectos que se referem à construção corporal em academias de ginástica à luz das falas de nossas entrevistadas. Na última parte, discutimos a microfísica da supervitalidade em academias de ginástica a partir das práticas e estratégias de construção estética do corpo. Desse modo, pretendemos não apenas contribuir para o debate sobre o culto ao corpo, mas também animar uma discussão sobre as relações de poder que fundamentam a ordem biopolítica de construção de corpos nos dias de hoje.

\section{Metodologia}

Os resultados utilizados nesta reflexão fazem parte de um estudo de campo realizado em seis academias de ginástica e musculação 
localizadas na região metropolitana da cidade do Recife ${ }^{2}$. Tomando como base a analítica do poder, proposta por Foucault (2004), a pesquisa de campo com caráter exploratório teve como objetivo analisar as operações biopolíticas que possibilitaram a inserção da construção de corpos belos.

Focalizamos o fenômeno em academias de ginástica devido ao seu reconhecido papel enquanto lugar de construção de corpos belos e por ser um lugar de intervenção específico da Educação Física. O processo de escolha das academias de ginástica ocorreu de forma randômica, obedecendo a um critério de localização de acordo com as áreas político-administrativas da cidade do Recife. Adotamos como critérios de inclusão a estrutura física da academia e o valor da mensalidade.

A seleção dos sujeitos foi realizada a partir de três critérios de inclusão: freqüentar a mesma academia de ginástica a pelo menos um ano sem interrupção, assiduidade (realizar exercício físico três vezes por semana) e gênero (feminino). Realizamos a pesquisa com mulheres, pois, historicamente a produção do corpo, especificamente do ponto de vista da beleza, foi entendida como prática de legitimação da feminilidade e forma de dominação social da mulher (WOLF, 1992). Nos últimos anos, todavia, a construção da beleza tem sido compreendida positivamente como estratégia de auto-satisfação, autocontrole e aceitação social (COSTA, 2004; THROSBY, 2008).

Para compor este artigo selecionamos propositalmente seis sujeitos devido ao conhecimento dos discursos já submetidos a uma análise de enunciados, bem como por entendermos que estes discursos podem ser considerados representativos para compreensão das relações de poder inerentes à produção estética do corpo em academias de ginástica. Seguimos as indicações de Gaskell (2008) sobre a delimitação do número de sujeitos da pesquisa. Segundo este autor é importante observar a existência de um número

${ }^{2}$ Os dados utilizados neste estudo são provenientes de uma dissertação mestrado em Educação Física. Utilizamos um roteiro de entrevista constituído por imagens relacionadas à temática do estudo. Participaram do estudo 30 mulheres praticantes de exercício físico em academias de ginástica na cidade do Recife, durante o segundo semestre de 2009. 
limitado de versões da realidade, pois, as representações de um grupo social são produtos de um compartilhamento, de uma experiência em comum que pode tornar o discurso repetitivo. Além disso, a grande quantidade de informações a serem analisadas supõe o risco de analisar os dados horizontalmente e não verticalmente.

Alcançar uma heterogeneidade em relação aos sujeitos foi fundamental para obter perspectivas provenientes de diferentes posições nos jogos de poder. Isso nos possibilitou uma leitura consistente sobre o fenômeno estudado, especialmente porque pudemos constatar que a construção de corpos belos representa um objetivo amplamente valorizado, apesar da diversidade sócio-econômica do grupo.

Quanto à técnica de coleta decidimos pelo uso de um roteiro de entrevista composto por imagens como estratégia para estimular a fala das entrevistadas da forma mais livre possível (EPSTEIN et $a l, 2006)$. Utilizamos a análise de discurso proposta por Foucault (2008) que está voltada à investigação de enunciados e às relações de poder. A seguir discutimos a supervitalidade, abordando sua construção nas academias de ginástica.

\section{EM BUSCA DA SUPERVITALIDADE E DO CORPO-MOTOR}

Focalizando os discursos obtidos no trabalho de campo, procuramos inicialmente discutir a supervitalidade como uma necessidade que caracteriza o sujeito contemporâneo. Para Virilio (1996), a idéia de supervitalidade possui um enfoque no conceito foucaultiano de biopolítica e significa investir sobre a vida para torná-la poderosa, ou seja, mais apta a desempenhar funções biológicas e de corresponder às exigências sócio-econômicas atualmente estabelecidas.

Entendemos que a busca pela supervitalidade pode ser compreendida como impulso biopolítico para melhorar a vida ou como resultado de uma saturação do sujeito que percebe seu próprio corpo enquanto uma barreira a qual impede um melhor desempenho sócio-econômico. Entretanto, o ímpeto pela supervitalidade está 
sempre associado à idéia de tornar a vida mais capaz, mais produtiva, mais longa, mais poderosa.

Hoje, quando a vida precisa ser acelerada como um motor, cabe aos sujeitos aumentar a velocidade dos próprios corpos, seja pelo cuidado de si ou pela adoção de medidas biotecnológicas voltadas ao aprimoramento do desempenho somático. Nesse sentido, as academias de ginástica apresentam recursos para maximizar o corpo ao oferecer uma estrutura pautada na superestimulação dos sentidos.

Sabe-se que atualmente as academias de ginástica apresentam uma proposta de intervenção renovada em relação à antiga tecnificação corporal. Do ponto de vista da sua organização e funcionamento, as academias configuram-se como locais voltados à prática dos mais diversos interesses, desde o físico-esportivo até a prática de conteúdos sociais (COELHO FILHO, 2000; HANSEN; VAZ, 2004; 2006).

Além disso, as academias de ginástica adotam estratégias renovadas para garantir a expansão de seu domínio comercial, constituindo-se enquanto territórios híbridos caracterizados pela inter-relação entre técnicas de dominação - que formam corpos dóceis e indivíduos obedientes - e estratégias de sedução - as quais motivam os sujeitos a buscar a superexcitação e a superprodução de suas forças. Nelas a lógica biopolítica divide espaço com a lógica da empresa considerada por Deleuze (1992) como uma forma ultrarápida de controle mediada pelo capital que visa, exclusivamente, criar novos mercados.

Confirmando a leitura de Deleuze, para D. (28 anos), as academias de ginástica são empresas que procuram fortalecer o seu poder econômico fazendo o uso de estratégias como a mídia e o uso de estereótipos sociais de corpo para convencer o consumidor: "[...] o objetivo das academias é esse não é? De trazer as pessoas pra dentro dela".

Na mesma ótica, Sassatelli (1999) considera que as academias 
de ginástica são lugares de negociação de identidade e significados corporais. Para a autora, as academias de ginástica são instituições comerciais que oferecem ao consumidor desde as mais tradicionais práticas de exercícios até as mais novas opções de treinamento físico e lazer. Nelas o corpo deixa de ser apenas um objeto de treino para se tornar um dispositivo simbólico fundamental dos sujeitos que delas participam.

A opinião de Sassatelli confirma as declarações das nossas entrevistadas, as quais consideram as academias de ginástica como lugar de lazer, de cuidado com a saúde, de culto à beleza e de socialização. É interessante perceber que em alguns discursos estes objetivos aparecem associados e remetem ao imperativo da melhoria corporal. Em outros casos, as observações das entrevistadas demonstram a busca pelas academias de ginástica enquanto forma de excitação.

Para M. C. (23 anos), o motivo que leva as pessoas a freqüentar academias de ginástica é, principalmente, a necessidade de melhorar o corpo. Quando questionada sobre a importância das academias de ginástica nos dias atuais, a entrevistada caracterizou a procura por investimentos corporais como uma loucura. "[...] É uma coisa louca. As pessoas são alucinadas acho até que é exagero. Acho que é porque libera adrenalina, as pessoas vêm pra um lugar diferente."

Segundo H. (52 anos) e M. Z. (76 anos), o exercício físico nas academias de ginástica é indispensável para viver bem. Quando questionamos as entrevistadas sobre como se sentiriam se deixassem de freqüentar academia, elas revelaram as seguintes respostas:

Péssima. Eu não consigo não. É como se fosse uma "cachaça". É vício realmente. Eu gosto muito principalmente da ginástica localizada. Sou dependente. Eu não teria o mesmo rendimento ou a mesma performance se eu não fizesse ginástica. A minha vida não iria fluir do jeito que vai sem o exercício (H., 52 anos).

Ah muito mal! Aqui eu me sinto muito bem, tenho muito bem- 
estar. Tanto pelo fato de estar aqui todo dia conversando com o pessoal quanto também pelo corpo porque aqui a gente adquire saúde e depois de certa idade tem que se cuidar (M. Z.,76 anos).

F. (40 anos), por sua vez, reconhece que as academias de ginástica oferecem serviços voltados à necessidade pessoal de obter prazer. Para ela as academias são formadas por "[...] pessoas diferentes cada um com seu estilo, cada um aqui deve ter o seu objetivo específico, mas todas procurando uma atividade seja em grupo ou não que lhe dê um certo tipo de prazer."

No íntimo das falas destacadas fica evidente uma associação entre a prática de exercício em academias de ginástica e interesses de cunho pessoal. O exemplo de F. (40 anos) referente à busca pelo prazer parece definir precisamente as intenções das entrevistadas. Através de diferentes meios objetiva-se alcançar uma forma de estimulação desejada e com isso obter níveis de satisfação corporal. Em outras falas como nas de H. (52 anos) e M. C. (23 anos), a presença de termos como "cachaça", "vício", "liberar adrenalina" apontam inicialmente para uma função compensatória das academias de ginástica que parece estar vinculada às ocupações do cotidiano. Um segundo entendimento remete à necessidade da experiência excitatória e à busca pelo prazer através das sensações corpóreas.

Nesse sentido, Virilio (1996) considera que a demanda por experiências superexcitatórias é decorrente do sedentarismo das sociedades contemporâneas, visto que a tranqüilidade da civilização exige naturalmente um acréscimo de excitação através do vigor físico e do esforço muscular. De forma semelhante, Costa (2004) considera que a satisfação e o prazer, obtidos através da produção corporal, representam "um aumento no tônus da vontade de sentir", vinculado a uma nova disciplina do corpo que "sempre traz vantagens e jamais atribuições".

Não obstante, o principal aspecto a ser ressaltado é o reconhecimento do exercício físico como estratégia para causar mais disposição e para melhorar o corpo. De maneira geral, verificamos nas falas das entrevistadas que a prática de exercício traz benefícios que aprimoram a performance em atividades diárias. 
Ele faz bem ao meu organismo, tem dosagens de glicose, colesterol que você tem que ter controle. Em termos de problema de joelho, eu corro bem e tenho agilidade. Você sabe né? Quando chega a idade, as articulações ficam mais pesadinhas, mas eu me sinto bem. Inclusive muitas vezes na academia eu me comparo com as meninas mais novas. E faz bem à cabeça também (H., 52 anos).

Ter uma auto-estima melhor, que passa por essa questão da imagem, e também as endorfinas e tal que fazem você se sentir bem. Eu acho tudo de bom e não sei como tem pessoas que não fazem exercício (F. M. 36 anos).

Já neste momento é possível observar a valorização da supervitalidade através da aquisição de um alto rendimento corporal, associado a um estado prolongado de bem-estar (VIRILIO, 1996; COSTA, 2004). Para além dos benefícios do exercício físico, o próprio fato de freqüentar as academias de ginástica pode ser considerado uma forma de buscar supervitalidade. Abordamos essa questão no momento seguinte, discutindo, a partir dos discursos analisados, as formas de superexcitação que compõem as academias de ginástica.

\section{A MICROFÍSICA DA SUPERVITALIDADE EM ACADEMIAS DE GINÁSTICA}

Nas palavras de Foucault, poderíamos dizer que a academia de ginástica é mais um diagrama de poder que age através do olhar, da vigilância, da correção dos movimentos, tendo por finalidade a introspecção de técnicas e condutas. Contudo, há nelas uma arquitetura, uma disposição de artefatos pensados para favorecer a maximização dos corpos que caminham nas esteiras, que pedalam nas bicicletas ergométricas, que elevam e aceleram pesos e alavancas.

Para Hansen e Vaz (2006), as academias de ginástica conjugam um vasto território de práticas e técnicas que produzem o corpo, seja na materialidade da sua natureza e cultura ou no conjunto de representações que incidem sobre ele. 
Se o corpo sofre cuidados específicos na sociedade contemporânea - tanto no cruzamento privilegiado das sociedades disciplinares, quanto no registro de algo regrado das sociedades de controle -, é nas academias que ele ganha centralidade máxima, quando homens e mulheres fazem-se em pedaços somáticos a serem investidos de modo específico, configurando um ambiente geograficamente estruturado de acordo com as regiões anatômicas sacralizadas pelas personagens que ali convivem (HANSEN; VAZ, 2006, p. 134).

Nessa perspectiva, entende-se que as academias não são apenas espaços de disciplina, mas de excitação constituídos por estratégias que visam estimular o corpo e os sentidos. Ao analisar sua estrutura, Sassatelli (1999) considera que o ambiente das academias é projetado inteiramente como espaço especializado que está relativamente separado da realidade externa, pois, dentro de suas fronteiras há uma organização do tempo e do espaço que permite um certo isolamento. Não obstante a estimulação é permanente.

F. (40 anos) apresenta um relato sobre as diferentes experiências de excitação que se pode obter em academias de ginástica. Ao ressaltar o fato de que a prática de exercício físico em academias causa maior disposição, leveza e auto-satisfação com a aparência corporal, ela destaca a importância das sensações através dos investimentos corporais.

Eu gosto das músicas, eu gosto de sentir a dorzinha depois do treino, eu sinto prazer não acho uma coisa sacal [...] eu gosto do exercício para mim é uma terapia mesmo. Muitas vezes você está triste aí você vai correr na esteira então você melhora muito aquela angustia que você está sentindo. É uma coisa terapêutica eu acho. Tanto em grupo às vezes pra fazer uma aula de dança ou outro tipo de esporte que não seja musculação, porque às vezes a musculação se você não gosta muito você acha monótono realmente.

Trata-se aqui não somente de sentir os efeitos do exercício durante a atividade, mas também de torná-los duradouros. É possí- 
vel considerar nesta fala a necessidade de sentir mais fortemente os reflexos do esforço físico. O prazer provocado pela "dorzinha", a música, a própria possibilidade de mudar de exercício quando este se torna chato, remetem à supervitalidade.

Nas falas aparecem ainda referências a diferentes tipos de estimulação que estão associados de forma direta às características da sociedade contemporânea. O individualismo e o sedentarismo, considerados como situações comuns do sujeito hodierno, sofrem rupturas nas academias de ginástica. Nesse sentido, a socialização se destaca como uma maneira de se relacionar com pessoas num espaço voltado ao cuidado com o corpo. O convívio social nas academias é inclusive utilizado como estratégia de sedução, tendo em vista o alto grau de distanciamento entre as pessoas verificado nos últimos anos (SABINO, 2002).

[...] na verdade a academia é também um meio social em que você interage com outras pessoas também. Tem o meio da paquera, tem o meio dos amigos, de conversa. Acho que hoje em dia virou praticamente um meio, não um clube, mas um local de encontros que as pessoas também usam como forma de cuidar do corpo, mas não só para isso. É uma desculpa para você sair de casa, para você conhecer pessoas novas, para você interagir com outras pessoas também. (M. 25 anos).

Em relação à interação social, ressaltamos ainda o valor atribuído à interação professor-aluno nas aulas. Esta interação foi referida nas falas ao mesmo tempo como incentivo à adoção de um estilo de vida saudável e como forma de melhorar os resultados do exercício.

Vejamos o que diz M. Z. (76 anos) sobre a relação professoraluno: "[...] Às vezes a gente vê academias em que o professor deixa tudo a mercê dos alunos, põe lá o exercício para a gente seguir e não corrige, não chama a atenção do pessoal. Aí a gente se sente perdido e muitas vezes fazemos os exercícios de forma errada". M. C. (23 anos) enfatiza a importância do treinamento personalizado enquanto meio para se ter bons resultados com maior 
segurança. "Falando em relação ao personal, eu acho muito importante. Já o professor, sei lá, eu acho que a orientação é muito vaga, muito solta. Já o personal não. Ele é aquela pessoa que fica do seu lado corrigindo os exercícios".

De acordo com Bossle (2008), a atuação do personal trainer está direcionada a extrapolação da relação profissional, fato que o torna um cuidador especialista que assume a responsabilidade pela saúde de seu cliente. Responsabilidade esta que se manifesta não apenas pela aplicação de técnicas, mas por uma experiência mais intensa de amizade e orientação.

Apesar da excitação associada à interação social, alguns autores como Sabino (2002) e Hansen e Vaz (2006) consideram as academias como lugar de agenciamento e exibição de corpos biotecnologicamente aprimorados. Sabino, em especial, aborda as questões ritualísticas do cuidado com o corpo e analisa o uso de drogas anabolizantes para tornar o corpo mais forte, belo e poderoso e promover uma hierarquização no espaço microfísico das academias. Na sua leitura, as academias de ginástica atuam como palco em que os corpos superdesenvolvidos confirmam seu status de poder sobre os corpos "normais" dos iniciantes. Em relação aos alunos iniciantes, Sassatelli (1999, p. 238) reforça que as próprias academias instituem hierarquias que permitem aos alunos experientes exercer poder sobre os mais novos.

Seguindo as recomendações de Sabino, Hansen e Vaz discutem aspectos da hierarquia de corpos considerados "sarados" na microfísica das academias de ginástica. Confirma-se, nesse sentido, o uso da imagem do corpo como forma de poder e entendimento do próprio poder enquanto jogo, por meio do qual os sujeitos ocupam posições diversas e reversíveis (FOUCAULT, 2004; 2006). As academias, portanto, funcionam como espaço de exibição do corpo, de desfile das formas e de quebra da intimidade. Nesse sentido, M. C. (23 anos) revela:

Eu já deixei de malhar na "Academia X" e na "Academia $Y$ " porque eu acho que é desfile de moda, não só eu como várias amigas minhas não gostam muito 
por causa disso. Por isso eu prefiro freqüentar uma academia menor. Algumas pessoas já me chamaram para entrar lá, mas eu acho que é desfile de moda e eu não gosto eu faço por saúde, outras pessoas não, fazem mais por beleza mesmo, para se mostrar.

Não obstante, a exposição do corpo parece ser uma forma de excitação que tem por finalidade potencializar as sensações corporais dos corpos expectadores. Nas falas analisadas pudemos perceber enunciados que reiteram esta idéia, uma vez que um dos efeitos da exibição de corpos saudáveis foi o sentimento de estímulo e de busca pela reprodução de uma aparência desejada. A fala de F. (40 anos) revela esse fato.

Às vezes numa academia não tem tanta gente bonita e tal aí, de repente, chega uma mulher bonita que é malhada também e você se admira. Não é que você vai ficar com inveja da pessoa, mas ela passa a ser um estímulo então às vezes é bom você malhar numa academia em que você é uma pessoa que se sobressai. É um estímulo para você treinar junto de uma pessoa que tem o corpo legal que malha todo dia.

Percebe-se que a influência de uma imagem que representa um corpo dotado de supervitalidade, como o corpo de quem malha, funciona como estímulo para reforçar os investimentos direcionados sobre si mesmo. É possível entender esse fato enquanto efeito de poder desencadeado pela necessidade de buscar a supervitalidade a partir da aparência, mas levando em consideração os benefícios fisiológicos e sociais que isso pode trazer.

Ressaltamos ainda que as academias enquanto espaços microfísicos de poder apresentam uma base de elementos tecnológicos racionalmente definidos para possibilitar transformações corporais. Referimo-nos às máquinas e aparelhos de musculação que seguindo princípios da biomecânica e da ergonomia funcionam como verdadeiros instrumentos de "empoderamento" corporal. A interação homem-máquina nas academias pode ser interpretada como uma forma biotecnológica de aprimorar o próprio 
movimento. As polias, alavancas e pesos formam aparelhos complexos, mas que permitem vivenciar exercícios variados, mobilizar grupos musculares de forma isolada, enfim, maximizar a mobilização corporal observando os limites de cada um.

Estas máquinas de "empoderamento da forma física" levam o sujeito a vivenciar sua corporeidade em condições que superam o contexto já conhecido de ativação neuromuscular (VIRILIO, 1996). Em função do esforço orientado biotecnologicamente, o sujeito se vê exposto à aceleração de sua dimensão biológica na medida em que os resultados fisiológicos se concretizam com maior velocidade.

Vinculada à aceleração da dimensão biológica, a construção estética do corpo associada à aplicação de tecnologias médicas aparece também como uma das principais manifestações da busca pela supervitalidade nas frequentadoras de academias de ginástica. Verificamos esta tendência entre nossas entrevistadas, principalmente no que se refere ao uso de cirurgias plásticas ou uso de anabolizantes para produzir ou melhorar a beleza corporal. As declarações de F. (40 anos), ex-fisiculturista, e M. C. (23 anos), submetida à cirurgia bariátrica, revelam como a produção do corpo é também uma forma de obter poder por meio da supervitalidade do corpo:

Em relação ao anabolizante existe uma questão psicológica, não é que vicie, mas, realmente existe diferença, por mais que você faça dieta quando você está fazendo uso os seus resultados são melhores, a densidade de sua pele é melhor, a qualidade de sua pele fica melhor, sexualmente se sente melhor porque mexe com isso também. Tem o outro lado não é? Você não dorme tão bem, mas é melhor não dormir e ser magro. Então, por favor, não vamos dormir! Então eu acho assim mexe um pouco em relação ao prazer que te dá porque você vê o resultado mais rápido, você vê que o músculo incha mais rápido, você vê que a qualidade do corpo melhora, mas tudo com alimentação (F., 40 anos). 
Acho que eu tentei de todas as maneiras, tentei médicos, regime, vigilantes do peso, nutricionistas tudo o que você puder imaginar, eu já estava deixando de viver, aí eu tomei essa decisão que foi muito corajosa. Mas eu acho que eu já tinha chegado ao meu limite. Foi a melhor coisa que eu fiz e quando você vê o resultado melhor ainda (M. C. 23 anos).

A aplicação de biotecnologias para a construção de corpos belos revela uma dimensão da supervitalidade referente à aquisição de uma forma física "aprimorada" e à construção de um novo corpo. Destaca-se na fala de M. C. (23 anos) o uso de opções biotecnológicas, sendo a cirurgia de redução de estômago a única que possibilitou o domínio de sua aparência e a aquisição do desejo de ser magra.

Segundo Virilio (1996), o domínio da aparência remete à constatação de que o corpo não consegue acompanhar os projetos de vida que estabelecemos para nós mesmos. Foucault (1999), por outro lado, percebe o domínio da aparência como possibilidade de tornar o corpo mais poderoso. De acordo com as opiniões de nossas entrevistadas, a tomada de decisão sobre o cuidado da própria aparência corresponde a uma forma de cuidar de si e de se perceber como gestoras do seu próprio corpo.

Assim, a orientação das práticas de construção de corpos belos encontra-se profundamente associada à fruição corporal. A produção biotecnológica da beleza pode ser vislumbrada como uma saída adotada pelos sujeitos contemporâneos para usufruir de sensações associadas à exibição, ao elogio e à auto-satisfação decorrente de uma aparência corporal aprimorada.

\section{ConclusÃo}

De acordo com as falas analisadas foi possível perceber que ter poder significa investir na maximização do corpo. A supervitalidade se manifesta na busca pela experiência sensorial que potencializa a capacidade de sentir, e através do uso de biotecnologias para 
melhorar as funções corporais. Em relação às experiências que possibilitam alcançar estados de supervitalidade nas academias de ginástica, destacam-se o exercício físico, as práticas de socialização e a sua própria estrutura funcional.

Além destes aspectos, ressaltamos a excitação e o prazer obtidos pelo uso de biotecnologias como os anabolizantes que, voltados à maximização fisiológica, favorecem a construção de um corpo esteticamente destacado. Sobre as academias de ginástica, seu sucesso parece estar vinculado à necessidade que os sujeitos têm de transitar em espaços que preencham uma lacuna de superexcitação.

Apesar do atual vínculo entre supervitalidade, felicidade, sucesso social e aceleração corporal, é urgente refletir sobre o rápido avanço das biotecnologias nas sociedades ocidentais. Desse modo, destacamos a necessidade que a Educação Física tem de se aprofundar neste debate tratando a supervitalidade pedagogicamente enquanto um movimento histórico de afirmação da vida. Esta apropriação deve acontecer abordando os limites e excessos da construção corporal sem negar a intenção humana de tornar a vida mais potente e questionando sobre as reais intenções de produzir corpos capazes de pensar, agir e sentir cada vez mais intensamente.

The supervitality as a power: a view from the
gym clubs
Abstract: In this study we understand the supervitality
as a result of biopolitics. Currently we do not seek to
protect life, but to maximize it and make it powerful.
The aim of the research was to analyze the
manifestations of supervitality in gyms. Using the
theories of Foucault and Virilio, we found that subjects
invest biotechnologically on the body to obtain power,
improving their social and biological performances.
Keywords: Supervitality. Power. Gym Clubs.
Biopolitics

ovimento, Porto Alegre, v. 16, n. 03, p. 203-220, julho/setembro de 2010. 


Supervitalidad como poder: una mirada desde
los gimnasios
Resumen: En este estudio, entendemos la
supervitalidad como resultado de la biopolítica.
Actualmente, no sólo buscamos proteger la vida, sino
maximizar y hacerla más poderosa. El objetivo de la
investigación fue analizar las manifestaciones de la
supervitalidad en los gimnasios. Usando las teorías
de Foucault e Virilio, encontramos que lo sujeto invierte
biotecnológicamente en el cuerpo para obtener poder,
enriqueciendo su bienestar social y biológico.
Palabras-clave: Supervitalidad. Gimnasios. Poder.
Biopolitica

\section{REFERÊNCIAS}

BOSSLE, Cibele. O personal trainer e o cuidado de si: uma perspectiva de mediação profissional. Movimento, Porto Alegre, v. 14, n. 1, p. 187-198, jan./abr. 2008.

COELHO Filho, Carlos Alberto de Andrade. O discurso do profissional de ginástica em academia no Rio de Janeiro. Movimento, Porto Alegre, n. 12, p. 14-25, 2000.

COSTA, Jurandir. O vestígio e a aura: corpo e consumismo na moral do espetáculo. Rio de Janeiro: Garamond, 2004.

DELEUZE, Gilles. Conversações: 1972-1990. Rio de Janeiro: Ed. 34, 1992.

EPSTEIN, Iris et al. Elicitation Interview (PEI): using photos to elicit children's perspectives international. Journal of Qualitative Methods, v. 5, n. 3. sept. 2006.

FOUCAULT, Michel. Vigiar e punir: história da violência nas prisões. Petrópolis: Vozes, 2004.

A arqueologia do saber. Rio de Janeiro: Forense Universitária, 2008.

2006.

A história da sexualidade I: a vontade de saber. São Paulo: Graal,

Microfísica do poder. Rio de Janeiro: Graal, 1999.

GASKELL, George. Entrevistas individuais e grupais. In: BAUER, M.; GASKELL, G. Pesquisa qualitativa com texto, imagem e som: um manual prático. 7 . ed. Petrópolis: Vozes, 2008. p. 64-89.

HANSEN, Roger; VAZ, Alexandre. Treino, culto e embelezamento do corpo: um estudo em academias de ginástica e musculação. Revista Brasileira de Ciências do Esporte, Campinas, v. 26, n. 1, p. 135-152, set. 2004.

Vovimento, Porto Alegre, v. 16, n. 03, p. 203-220, julho/setembro de 2010. 
. "Sarados" e "gostosas" entre alguns outros: aspectos da educação de corpos masculinos e femininos em academias de ginástica e musculação. Movimento, Porto Alegre, v. 12, n. 1, p. 133-152, jan./abr. 2006.

NORA, Simon; MINC, Alain. A informatização da sociedade. Rio de Janeiro: FGV, 1980.

SABINO, César. Anabolizantes: drogas de Apolo. In: GOLDENBERG, M. (Org.). Nu e vestido. Rio de Janeiro: Record, 2002.

SASSATELLI, Roberta. Interaction order and beyond: a field analysis of body culture within fitness gyms. Body \& Society, v. 5, n. 2-3, p. 227-248, 1999.

SPIELVOGEL, Laura. The discipline of the space in a Japanese fitness club. Sociology of Sports Journal, v. 19, p. 189-205, 2002.

THROSBY, Karen. Happy re-birthday: weight loss surgery and the 'new me'. Body \& Society, v. 14, n. 01, p. 117-133, 2008.

VIRILIO, Paul. A arte do motor. São Paulo: Estação Liberdade, 1996.

WOLF, Virgínia. 0 mito da beleza: como as imagens de beleza são usadas contra as mulheres. Rio de Janeiro: Rocci, 1992. 